\title{
REPRESENTING SOCIAL RESPONSIBILITY IN EXTENDED SOCIAL NETWORK ESPECIALLY CONSIDERING TRANSPORT APPLICATION POSSIBILITIES
}

\author{
Arpad Torok ${ }^{1}$ \\ ${ }^{1}$ Budapest University of Technology and Economics, Department of Transport Technology and \\ Economics, Budapest, Hungary
}

Received 18 October 2016; accepted 2 August 2017

\begin{abstract}
The objective of this article is to the demonstrate a complex system that makes it possible for users to reduce their costs expenditures when purchasing specific goods by making society-aware decisions. The system bases the estimation process of social-economical values that are proportional to the extent of social awareness on external cost calculation methodology. Basically, the concept of the described intelligent system places the elements aimed to boost external savings and profits and to motivate socially aware decisions around the "concept of returning customers".
\end{abstract}

Keywords: social responsibility, social awareness, concept of returning customers.

\section{Introduction}

The objective of this article is the demonstration of a complex system that opens up the possibility for users to reduce expenditures when purchasing specific goods by making society-aware decisions, thus creating social savings.

In order to achieve this goal, a system structure needs to be created that is suitable for the monitoring and measuring of daily individual decisions, for the estimation of the extent and effects of society-awareness when making those decisions, for the monetizing of those effects, and for the display of the social-economical value proportional to the estimated extent of social awareness.

The system declares the individual choices as socially aware decisions if the decision maker, besides trying to realize his/her own goals, also serves the wellbeing of the society and considers the interests of the society as a whole (Crane, 2008).

In a few typical sectors, for example in insurance, health care, transportation (Junevičius, et al., 2009) and sport, some of the characteristic features of socially aware processes, such as the common financing of common goals are traditionally present. It is easy to see that in any insurance activity, the insured individuals, organizations or groups form a surety community, with the basic interest of minimizing risk factors (Sipos, 2014). Generally, it's also true that the public financing rate of the health care, transportation and sport sectors is significantly higher than that of the rest of the sectors. Of course, there are also sectors out there where the aforementioned

\footnotetext{
${ }^{1}$ Corresponding author: torok.arpad@mail.bme.hu
} 
characteristic features of social awareness are less explicit, however, they still exist in the background. Such sector is for example commerce, where during the consumption process the consumer can ponder the external effects of the purchase of each product or service.

As a summary, the aim of the aforementioned system is to motivate consumers to opt for the purchase of goods and services that contribute to the largest possible external savings and profits, in other words, the manifestation of a value proportional to the estimated extent of social awareness.

\section{Methodology}

The system bases the estimation process of social-economical values that are proportional to the extent of social awareness on external cost calculation methodology. Considering the definitions of welfare economics, external effect is the factor that, in addition to the directly affected participants of an economic activity, indirectly affects the wellbeing of another party (Munilla et al., 2005). In other words, in the present system (Monzon, et al., 2013) externality (an external economic effect) is defined by a factor that, as a result of the economic activities of an individual, an organization or a group, affects the wellbeing of another person, organization or group not affected by the economic and financial processes of the activity itself. Based on ISO 26000 (ISO, 2010), this methodology breaks down individual socially aware decisions to the following economical, ecological and social categories:

1. the economical category includes for example the aspects of economic performance and the indirect economic effects (an indirect effect is for example the decrease in resource prices due to the resource-saving decisions made by micro-economical participants);

2. the ecological category includes for example the aspects of energetics, harmful substance emission, waste management and transportation (European Commission, 1995);

3. the social category includes for example the aspects of health care, security, equal opportunities and human rights.

\section{Evaluation}

Basically, the concept of the described intelligent system places the elements aimed to boost external savings and profits and to motivate socially aware decisions around the "concept of returning customers".

The platform provided by the intelligent system opens up opportunities for cooperation between customers from the demand side of the market and individuals or corporations from the supply side thereof. One of the basic elements of the concept is that the participants of the economy and the products and services they offer are classified in one of these groups upon joining the system. The consumers access the offered products and services via the platform provided by the system. This is where the social-economical value resulting from socially aware decisions manifests in the market processes, in other words this is where the value of social profits and savings are deducted from the price of the products and services. However, it is important to note that the system should also promote social values that are hard to monetize, this way user behaviors such as generosity, politeness or responsible decision-making and socially aware lifestyle can be assessed. 
The main objective of the concept is to build a consumer basis that is open to socially aware processes to purchase the products and services that create social savings and profits (Figure 1). The consumer joining the system supports the socially responsible participants of the economy by choosing the socially useful product or service out of the service- or product range offered in the given market segment. As another basic rule of the "returning customer concept", when a customer repeatedly chooses to purchase their offered goods, the supported participants of the economy discount the social savings resulting from the selling of their products. The socially aware sales and purchases are realized via the system's marketplace, which also provides opportunities for consumers to exchange the various social category's savings accumulated as a result of socially aware purchases.

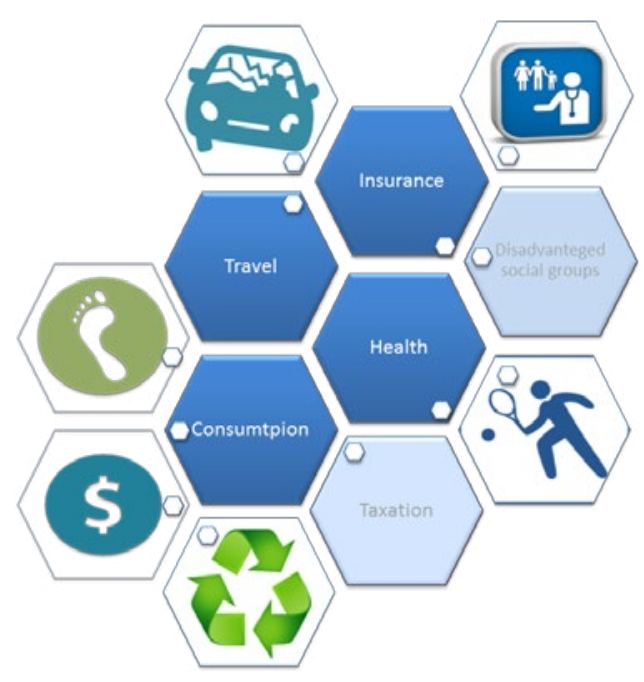

Fig. 1.

Covered and Possibly Coverable Social-Economic Fields of the System

The basic concept provides reliable returning customer groups for individual or corporate suppliers, who are also dedicated to the social field characterizing the operation of the given participant of the economy. Additionally, it provides opportunities for socially aware consumers for the display of the social savings and profits resulting from their decisions in the market processes.

Supporting the concept and to enhance its usability, with special regards to the realization of the marketplace, the intelligent system should be characterized by a modular structure. Furthermore, during the realization of the system processes, cooperation of the following modules is imperative (Figure 2):

1. the "individual" module monitors and measures the routine individual decisions;

2. the "participant of the economy" module is responsible for the discounts and motivation opportunities provided by 
the market- or community participants of the economy;

3. the "value added" module enables the assessment and monetization of the extent of the effects of social awareness and the establishment of the socialeconomical value proportional to the estimated extent of social awareness, as well as the indication of social savings and profits in the social processes;

4. the "network" module allows for the network sharing of individual information and profiles and enables the promotion and realization of socially significant projects and community communication;

5. the "business" module is responsible for the creation and market-based relay of information valuable for the profitoriented participants of the economy, with special regards to the areas of marketing and market-research.

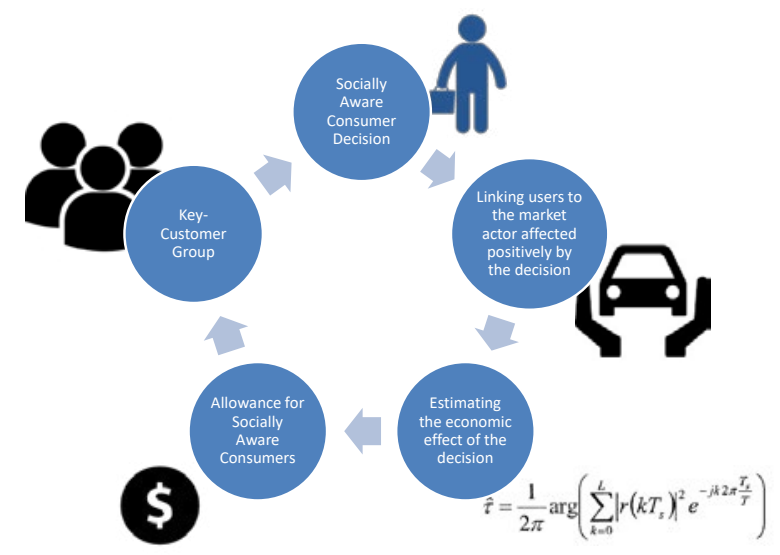

Fig. 2.

Basic Concept Behind the Modular Structure

The modular structure supports the following system functions:

1. Measurement of external effects of consumer decisions (Beke, et al., 2014);

2. Estimation of external expenditures of consumer decisions;

3. Generating of sharable user profile, based on consumer decisions affecting the society;

4. Consideration of external savings and profits associated with purchases during future purchases;

5. Possibility of exchange of external savings of different social categories between users, while considering the demand for external savings of different social categories, with special regards to the supply-demand relation;

6. Advertising of socially significant projects and community communication;

7. Analysis of aggregated consumer decisions, market-research (Lógó, 2009);

8. Decrease of environmental pollution, preference given to environmentfriendly products and services;

9. Reducing energy-consumption, giving preference to energy-efficient products and services; 
10. Stopping or slowing down unfavorable social processes (for example segregation, discrimination, unequal opportunities) and giving preference to products and services strengthening social development (e.g. equal opportunities, wheelchair-friendly facilities).

The realization of the system calls for the following research and development actions (Figure 3):

1. Development of system elements suitable for measuring the external effects of consumer decisions, using already existing technology (smartphones, online shopping);

2. Defining the scientific methodology for the estimation of external effects of consumer decisions;
3. Creating a community network suitable for generating sharable user profiles;

4. Defining the scientific methodology underlying the consideration of external savings and profits associated with purchases;

5. Creating a mathematical model allowing the exchange of external savings associated with different social categories, while considering the demand for external savings of different social categories, with special regards to the supply-demand relation;

6. Development of a module suitable for the promotion of socially significant projects and community communication;

7. Development of a market-research methodology suitable for the analysis of aggregated consumer decisions.

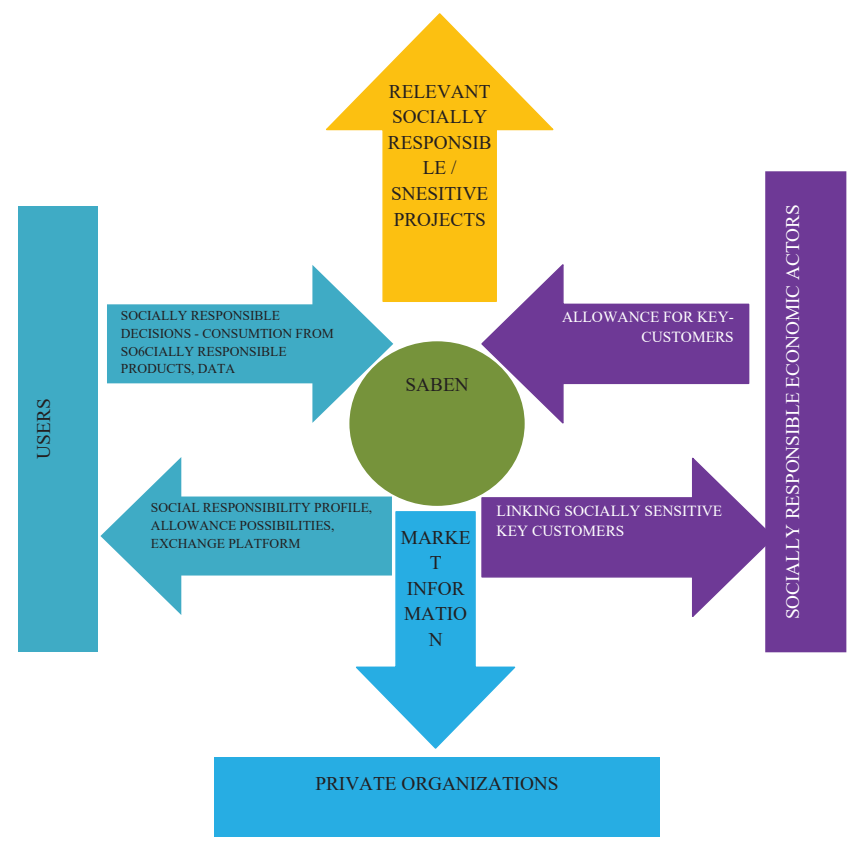

Fig. 3.

System Processes 


\section{Conclusion}

Summing up the article we can conclude that the objective of research is the demonstration of a complex system that opens up the possibility for users to reduce expenditures when purchasing specific goods by making societyaware decisions, thus creating social savings.

The system bases the estimation process of social-economical values that are proportional to the extent of social awareness on external cost calculation methodology. Considering the definitions of welfare economics, external effect is the factor that, in addition to the directly affected participants of an economic activity, indirectly affects the wellbeing of another party (Munilla et al., 2005).

Basically, the concept of the described intelligent system places the elements aimed to boost external savings and profits and to motivate socially aware decisions around the "concept of returning customers".

The platform provided by the intelligent system opens up opportunities for cooperation between customers from the demand side of the market and individuals or corporations from the supply side thereof. One of the basic elements of the concept is that the participants of the economy and the products and services they offer are classified in one of these groups upon joining the system.

The consumers access the offered products and services via the platform provided by the system. This is where the social-economical value resulting from socially aware decisions manifests in the market processes, in other words this is where the value of social profits and savings are deducted from the price of the products and services. However, it is important to note that the system should also promote social values that are hard to monetize, this way user behaviors such as generosity, politeness or responsible decision-making and socially aware lifestyle can be assessed.

\section{References}

Beke, B. M.; Sipos, T.; Torok, A. 2014. The Mathematical Modelling of the Road Safety Equipment's Market Penetration, American Journal of Vehicle Design 2(1): 1-6.

Crane, A. 2008. The Oxford handbook of corporate social responsibility. Oxford ; New York: Oxford University Press. 590 p.

European Commission. 1995. Towards Fair and Efficient Pricing in Transport, Green Paper, Brussels.

ISO. 2010. ISO 26000 - Social responsibility.

Junevičius, R.; Bogdevičius, M. 2009. Mathematical modelling of network traffic flow, Transport 24(4):333-338.

Lógó, E. 2009. Usability test with non conventional goals-success and expenditure indicators, Periodica Polytechnica, Social and Management Sciences 17(2): 67.

Monzon, A.; Hernandez, S.; Cascajo, R. 2013. Quality of bus services performance: benefits of real time passenger information systems, Transport and Telecommunication 14(2): 155-166.

Munilla, L.S.; Miles, M.P. 2005. The corporate social responsibility continuum as a component of stakeholder theory, Business and society review 110(4): 371-387.

Sipos, T. 2014. Coherence between Horizontal and Vertical Curves and the Number of the Accidents, Periodica Polytechnica, Transportation Engineering 42(2): 167. 